\title{
Correction to: Uncommon presentations in ANCA vasculitis: clinical characteristics and outcomes
}

\author{
Veena S. Katikineni ${ }^{1}$ - Sam Kant ${ }^{2}$ - Eric J. Gapud ${ }^{3} \cdot$ Brendan Antiochos $^{3} \cdot$ Rebecca L. Manno $^{3} \cdot$ Michael Phillips $^{3}$. \\ Philips $\mathrm{Seo}^{3} \cdot$ Duvuru Geetha ${ }^{4}$ (D)
}

Published online: 23 May 2019

(C) International League of Associations for Rheumatology (ILAR) 2019

\section{Correction to: Clinical Rheumatology \\ https://doi.org/10.1007/s10067-019-04568-4}

The family name of the co-author of the article mentioned above was incorrectly spelled. The correct name should have been "Veena S. Katikineni" instead of "Veena Katikeneni". The original article has been corrected.

Publisher's note Springer Nature remains neutral with regard to jurisdictional claims in published maps and institutional affiliations.

The online version of the original article can be found at https://doi.org/ 10.1007/s10067-019-04568-4

Duvuru Geetha

gduvura@jhmi.edu

Inova Fairfax Hospital, Annandale, VA, USA

2 University of Maryland Midtown Campus, Baltimore, MD, USA

3 Division of Rheumatology, Department of Medicine, Johns Hopkins University, Baltimore, MD, USA

4 Division of Nephrology, Department of Medicine, Johns Hopkins University, Baltimore, MD, USA 